\title{
Physical-Chemical Characterization and Thin Layer Chromatographic Comparison of a Local Propolis with the Mangifera indica Resin
}

\section{Dailen Guanche Gallardo*, Mario Fajardo, Yaneisy Naranjo Alonso, Lilian San Martín Echemendía, Jam Montalvan Copello}

Beekeeping Research Center. El Cano. Arroyo Arenas. La Lisa, Postal Code 19190, Havana City, Cuba

\section{Article Information}

Received 24 September 2019

Received in revised form 24 Jan 2020

Accepted 31 January 2020

Keywords:

Propolis,

Mangifera indica,

Characterization,

Thin Layer Chromatography

Corresponding Author:

E-mail

dailen.guanche2911@gmail.com

Mob.: $x x x x x x x x x x x$

DOI: 10.20510/ukjpb/8/i1/1581041940

\begin{abstract}
Mango (Mangifera indica) is an abundant tree of Cuban flora that is known for many healing properties and a deposit of bees as a source of raw materials for the propolis production. This work aimed to determine if the resin of mango felled bark was used by honeybees in the elaboration of a specific type of propolis. This could be possible by qualitatively comparison of its samples with the mango resin and the quality of this propolis through its physicochemical characteristics. To do this, propolis was collected and hydroalcoholic extracts were prepared. From this, botanical origin was determined by the technique of thin layer chromatography. Humidity, oxidation index, wax, resin and mechanical mixtures were evaluated from raw material. Results demonstrated that the samples of propolis collected presented a chromatographic profile similar to mango resin. In the samples of propolis, it was determined that quercetin and mangiferin are present in their qualitative composition of secondary metabolites. On the other hand, the mango propolis satisfies the requirements established by international regulations for good quality propolis in terms of humidity, oxidation index and mechanical mixtures.
\end{abstract}

\section{Introduction}

Propolis is a resinous material of varied coloration that has been studied extensively in recent years. It is elaborated by honeybees for different purposes including the protection of the hive against pathogenic microorganisms. The different properties of propolis have attracted the attention of numerous scientists, who have published on the chemical composition ${ }^{1,2}$, the biological activities ${ }^{3}$ and therapeutic uses of propolis ${ }^{4}$.

The materials available for bees in the production of propolis are substances actively secreted by plants as well as substances exuded from wounds in plants. The composition of the plant source and its availability will determine the chemical composition and concentrations in the propolis. For example, in Brazil there is a variety of green propolis in which artepilin C predominates as a chemical compound and has its origin in the plants of Baccharis spp ${ }^{5}$. In Europe, North America and some Asian regions that do not belong to the tropics, poplar propolis has been characterized. Their esters and flavonoids are characteristic of plants belonging to Populus spp $p^{6}$. Also, in the tropical islands of the Pacific Ocean, propolis are very typical of their areas. The presence of prenilated flavanones as their main constituent, having as their main botanical source the Macaranga tanarius ${ }^{7}$.

Cuba has also conducted characterization studies of its propolis by the use of some advanced techniques as high performance liquid chromatography equipped with photodiode array detector (HPLC-PDA), Nuclear magnetic resonance (NMR) and PHLCElectrospray lonisation (HPLC-ESI). Most of the literature found refers to three types of propolis. Type I, brown, from which brownred extracts can be obtained and are characterized chemically by the main presence of nemorosone, a prenylated benzophenone with botanical origin from Clusia rosea. Type II, are red and in their chemical composition prevail the isoflavonoids, mainly vestitol, medicarpine, neovestitol and isosativan. And Type III or yellow, are characterized by the predominant presence of aliphatic compound, probably triterpenes ${ }^{8}$. 
Mango, or Mangifera indica, is an abundant fruit tree species in Cuba. It has been possible to observe the process of collecting exudates from this plant by the bees. Characterization studies of Mangifera indica extracts have shown the presence of xanthones, benzophenones and flavonoids ${ }^{10,11,12}$ and its medical and pharmacological properties.

A comparative study of mango bark resin with propolis of the same origin has not been analyzed until now. In the experimental apiary of the Beekeeping Research Center (CIAPI for its acronym in Spanish), which is located in a plantation with a very significant representation of Mangifera indica, we have observed honeybee collecting resin from felled mango trees. Samples of this resin and propolis from the hives of the same apiary were taken. The aim was to determine if the resin of the mango felled bark was used by the bees for the elaboration of a specific type of propolis. This could be possible by the qualitative comparison of its extracts with the mango resin and the quality of this propolis through its physical-chemical characteristics.

\section{Material and Methods}

\subsection{Obtaining propolis and mango resin}

In the month of March, after four weeks of cleaning the hives that belong to the study apiary of the Beekeeping Research Center in Cuba $\left(23^{\circ} 1^{\prime} 43.80^{\prime \prime} \mathrm{N}\right.$ of latitude and $82^{\circ} 27^{\prime} 28.61^{\prime \prime} \mathrm{O}$ of longitude), resin samples were taken by scraping the felled barks of Mangifera indica trees. These are arranged no more than 20 meters from the study hives. Propolis collection was carried out at the same time using the same method, scraping, and samples only were taken on the tops or roof of the study hives.

\subsection{Samples preparation}

Three samples of resin and 12 of propolis were taken to the laboratory where they were placed in a freezer overnight and subsequently macerated. This macerates were put in vials and $99 \%$ alcohol added to a $1 \mathrm{~g} / 5 \mathrm{ml}$ ratio. They were left in extraction at room temperature, protected from light and with occasional agitation for 24 hours, then the solution was filtered and the extract saved until used. These samples were called mango resin and mango propolis.

\subsection{Reference substances}

Nemorosone, quercetin and mangiferin standards were from Shaanxi Sciphar Hi-Tech Industry and Sigma-Aldrich. They were diluted in ethanol with an approximately 99,95 and $90 \%$ of purity was used respectively.

\subsection{Thin Layer Chromatografhy (TLC)}

Samples of mango resin, mango propolis and resin of mango (from procedure to determine resin in propolis in the section of Physicochemical characterization) were run in a TLC.

A glass chromatographic camera was used and worked at room temperature $\left(25-29^{\circ} \mathrm{C}\right)$. Silica gel plates on glass support were used for qualitative analyzes. The application was made with the use of capillaries with spontaneous drying of the applications. An upward runs was developed using three solvent systems as mobile phases: mixture hexane: ethyl acetate (3:2), another ethyl acetate: acetic acid: formic acid: water $(7: 1: 1: 1)$ and hexane: ethyl acetate $(7: 3)$.

Solvents hexane: ethyl acetate (7:3) and toluene: ethyl acetate: formic acid (6:5:1) were used for the two-dimensional TLC. The application was made one centimeter from the bottom edge and the run was approximately eight centimeters. The distance between each application was one centimeter. Result of all run profile of the samples was visualized through an UV lamp at 254 $\mathrm{nm}$. The exposure of the plates to iodine vapors was used as developer.

\subsection{Physicochemical characterization}

All analyzes were done following the methodology proposed by the Norma Argentina IRAM-INTA 15935-1 ${ }^{13}$. The tests were performed in triplicate and the results were expressed in percentages, except for the oxidation index that was expressed in seconds.

Humidity was determined using the thermogravimetric method. One gram of the raw propolis was weighed in a previously tared capsule and placed in an oven at $105^{\circ} \mathrm{C}$; subsequently, it was allowed to cool in a desiccator and the process was repeated until a constant weight was obtained (two successive weights should not differ by more than $\pm 5 \mathrm{mg}$ ).

The determination of extractable substances (wax) in n-hexane was carried out by weighing two grams of sample arranged in a cellulose cartridge; condensation was carried out using the soxhlet technique from a volume of $200 \mathrm{ml}$ of $\mathrm{n}$-hexane for six hours, then the volume left in the ball was measured, $10 \mathrm{ml}$ were taken, which were dried in an oven at $105^{\circ} \mathrm{C}$ and weight of dried wax was used to estimate its proportion in the total sample.

The procedure to determine resin was very similar. The remainder of each sample resulting from the extraction of extractable substances with hexane was placed in the body of a soxhlet extractor. A new ethanol extraction was performed. At the end, the ethanol content was brought to a volume of $100 \mathrm{ml}$. An aliquot was taken that was placed on plates and dried at $80^{\circ} \mathrm{C}$ and weight of dried wax was used to estimate its proportion in the total sample.

To determinate mechanical mixtures the insoluble residue retained in the cellulose thimble at the end of the soxhlet extraction process, was carried in an oven at $80^{\circ} \mathrm{C}$ until constant weight for determination.

The oxidation index was performed by weighing $0.1 \mathrm{~g}$ of the crude propolis sample and adding $2.5 \mathrm{ml}$ of ethanol. It was rested for an hour and $50 \mathrm{ml}$ of water was added by shaking before filtering. From this filtrate, two mililiters were taken, added $20 \%$ 
sulfuric acid solution and stirred for one minute. Finally, a drop of $0.1 \mathrm{~N}$ potassium permanganate was added and the chronometer was started while stirring constantly. The time, in seconds that the solution bring to discolor was recorded.

\section{Results}

\subsection{Thin Layer Chromatography (TLC)}

The TLC is a simple, economical and easiest available technique, widely employed in plants analysis. In our study, the TLC has been employed to qualitatively analyze the origin source of collected propolis from CIAPI's apiary and the presence of some of its secondary metabolites.

Although only three compounds were evaluated as standards (nemorosone, quercetin and mangiferin), the run profiles in the three solvent systems of mango resin and mango propolis extracts are very similar. Main differences were fundamentally found in the concentrations. Figure 1 shows the chromatographic behavior of the samples and the references substances using as a solvent the mix of hexane: ethyl acetate (3:2).

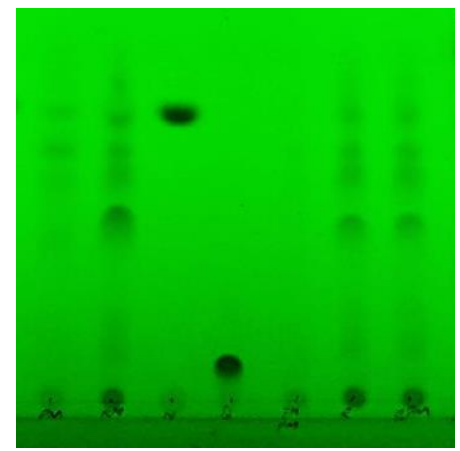

Fig 1: TLC $\lambda=254 \mathrm{~nm}$. Solvent hexane: ethyl acetate (3:2). Q: quercetin, $\mathrm{N}$ : nemorosone, PM: mango propolis, RM: mango resin, RPM: resin of propolis

In the plates, UV visualization allowed to see the patterns and the characteristic bands of the samples. Mango propolis, mango resin and resin of propolis (from procedure to determine resin in propolis) had a very similar chromatographic profile with a coincidence of six bands with equal $R_{f}$ suggesting the origin of propolis from mango resin.

Regarding the references substances employed, well-defined bands with similar $R_{f}$ to nemorosone were observed in mango resin, mango propolis and resin of propolis. The presence of quercetin was also observed although with bands of lower resolution.

In the chromatographic runs with mixture hexane: ethyl acetate (7:3), a less polar system, samples of mango propolis, mango resin and resin of propolis were applied together with the reference substance, nemorosone (Fig 2). They showed a significant diversity of separate compounds corresponding to different secondary metabolites. The three samples applied exhibited a chromatographic profile with seven coincident bands of equal Rf. Regarding the references substances employed, well-defined bands with equal $R_{f}$ to nemorosone were observed in the three samples.

The development of the bi-dimensional TLC with the third solvent system is showed in figure 3 . For this case, only the mango propolis was run. A first run was made with hexane: ethyl acetate (7:3) while in a second system was used the mixture toluene: ethyl acetate: formic acid (6:5:1).

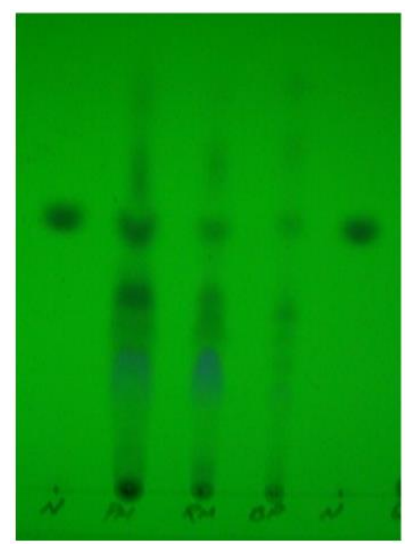

Fig 2: TLC $\lambda=254 \mathrm{~nm}$. Solvent hexane: ethyl acetate (7:3). $\mathrm{N}$ : nemorosone, PM: mango propolis, RM: mango resin, RPM: resin of propolis

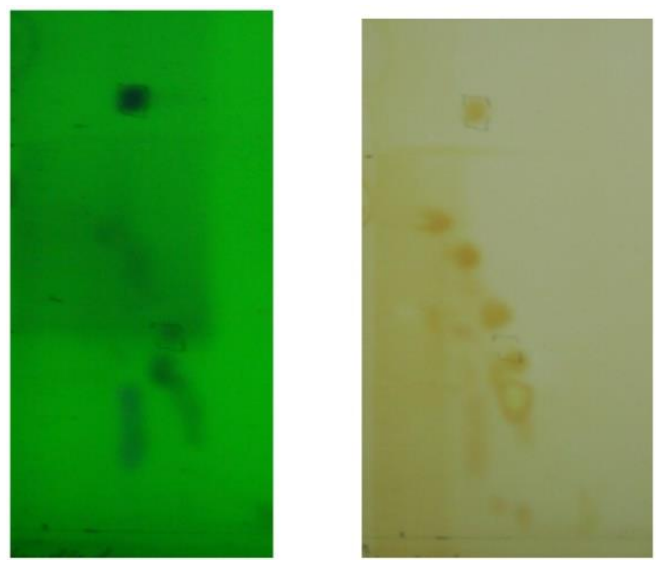

Fig 3: TLC. Solvent toluene: ethyl acetate: formic acid (6:5:1). A) $\lambda=254 \mathrm{~nm}$. B) developed with iodine vapors

The profile showed that the band appeared in the previous chromatographies with the same $\mathrm{Rf}$ as nemorosone standard does not correspond to this compound. In this case, when resolving the bands in two dimensions it was observed that is not the prenylated compound that appears in the bands identified with the nemorosone.

Samples of mango propolis, mango resin and resin of propolis were applied together with the reference substance mangiferin for runs with ethyl acetate: acetic acid: formic acid: water (7:1:1:1) (Fig 4).

The mangiferin, used as reference substance, could be observed in all samples applied.

In this case few bands were observed in addition to the mangiferin. However, some bands could be observed within the chromatographic profile of each sample. That coincide with 
mango propolis, mango resin and resin of propolis, forming a very similar profile in the distribution of the same.

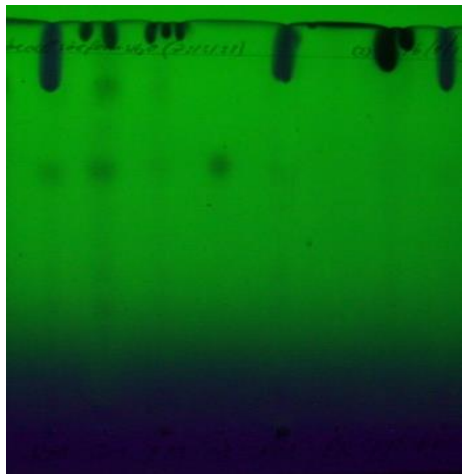

Fig 4. TLC $\lambda=254 \mathrm{~nm}$. Solvent ethyl acetate: acetic acid: formic acid: water (7:1:1:1). M: mangiferin, PM: mango propolis, RM: mango resin, RPM: resin of mango

\subsection{Physical-chemical characterization}

Table 1 lists the results of the different quality parameters analyzed. It indicates the mean value and the standard error for each parameter.

From this information it can be concluded that values for humidity, oxidation index and mechanical mixture were suitable for a propolis of good quality according to the international regulations consulted. The wax showed a mean above the highest value proposed by the same regulation whiles the resin under the lowest values. In both cases, despite the fact that values do not comply with the regulation, is notable to observer that even then the means are very close to the limits.

Table 1: Study propolis characterization and its comparison with standard values

\begin{tabular}{lccccc}
\hline $\begin{array}{l}\text { Physical-chemical } \\
\text { characterization }\end{array}$ & Humidity & Oxidation Index & Wax & Resin & Mechanical Mixture \\
\hline Propolis studied $^{*}$ & $5.7 \pm 0.9$ & $13.7 \pm 4,1$ & $39.4 \pm 6,6$ & $29.3 \pm 1,3$ & $23.5 \pm 6,09$ \\
Argentina Regulation $^{13}$ & $10 \% \max$ & 22 seconds max & $35 \% \max$ & $35 \% \min$ & $25 \% \max$ \\
Brazilian Regulation $^{25}$ & $8 \% \max$ & 22 seconds max & $25 \% \max$ & $35 \% \min$ & $40 \% \max$ \\
El Salvador Regulation & & & & & \\
\hline
\end{tabular}

\section{*Mean and Standard Deviation}

\section{Discussions}

The phytochemicals give different values of $\mathrm{Rf}$ in different solvent system, solving and given different profile in each one of them. The system of solvent used, were based on previous studies carried out by Cuesta-Rubio et $\mathrm{al}^{9}$ in their analysis of the typification of Cuban propolis.

In addition to the analyzed metabolites, a variety of bands were found, very well visible in the chromatographs. These corresponding to other compounds, probably of the flavonoid type that should be studied in the future. However, it was possible to verify the similarity of the chromatographic profiles of propolis with the mango resin by three solvent systems with different polarities (fig.1, 2 and 4). Proximity and availability of the resin of the Mangifera indica provided to the bees the necessary raw material to incorporate the compounds derived from it into their product.

It is well known the influence of the type of flora on chemical components of propolis, as a result, propolis from tropical region present a very particular chemical diversity. The Cuban propolis studies suggest the prevalence of brown propolis rich in polyisoprenylated benzophenones detected in the Clusia rosea plants ${ }^{9}$.
In the plates, the bands corresponding to the nemorosone were identified in mango propolis and resin of propolis with good resolution (Fig 1 and 2). No reports were found mentioning the presence of nemorosone as a secondary metabolite in Mangifera indica. Nevertheless, some characterization studies of compounds in Mangifera extracts have detected and isolated other prenylated benzophenones, iriflofenone and maclurine in a higher concentration ${ }^{10-12}$. But if we take into account the results in which Rf bands similar to nemorosone were found and the great representativeness of Mangifera indica throughout Cuba, an important contribution from these plants could be expected in the composition of brown propolis (type I).

Taking into account these antecedents and to be sure that the bands found in chromatographies were actually those corresponding to the nemorosone standard used or some other compound derived from it, a two-dimensional TLC was performed in which the second run was used a solvent system that according to reports of the literature solves the flavonoid bands well ${ }^{14}$.

The results observed in figure 3 clarified the dilemma previously proposed. The resolution of the bands in this system showed that there is no correspondence of any band with nemorosone standard in the propolis mango samples. Something important because in the previous TLC with a single solvent system it 
couldn't be determined if actually in the analyzed samples exist or not the presence of that compound. Due to this, it is recommendable to use more advanced methodologies to clarify this fact.

There are many study that recommends consuming the leaves, barks, seeds and fruit peel of the mango tree because the great quantity of medical, pharmacological and health benefit. The phytochemical analyzes of Mangifera indica report the mangiferin as the compound with the highest concentration; and a huge avalanche of evidence suggests its antioxidant, antiinflammatory, antidiabetic, hepatoprotective, gastroprotective and immunomodulatory effects ${ }^{15}$

In plates visualized with light at $254 \mathrm{~nm}$ (Fig 4) the presence of well-defined bands with identical Rf to mangiferin was observed in the resin of propolis and mango resin. It was possible to see clearer bands in mango propolis.

An increasing number of evidence on in vitro and in vivo studies support the affirmation that the parts of plants and its extracts exert diverse benefits that promote health. This same property that mangiferin confers to mango could be attributed to propolis of the same origin since it contains this metabolite.

In spite of the low resolution, bands corresponding to quercetin were observed in the mango resin sample. These coinciding with what was indicated in the literature about the presence of this metabolite in the Mangifera indica (fig. 1). In mango propolis they were observed as well as in the resin of propolis.

Quercetin is one of the important flavonoids present in more than twenty plants and is known by its anti-inflammatory activities ${ }^{16}$, anti-hypertensive and vasodilator ${ }^{17}$, anti-carcinogenic ${ }^{18}$, gastroprotector $^{19}$, anti-allergenic ${ }^{20}$, as well as their antifungal ${ }^{21}$ and antioxidant properties ${ }^{22}$

On the other hand, the quality of the propolis analyzed from physical-chemical parameters was good. Humidity values indicate the handling and environment in the recollection of propolis. This condition avoids the occurrence of mold and yeasts on its surface and the creation of contaminating products, which may be toxic and injurious to health ${ }^{23}$. In fact, humidity values from propolis samples were excellent with means below the maximum limits established by several international regulations.

The waxes, which are associated with a low quality of $\operatorname{tint}^{24}$, were above the maximum limits established by the international standards consulted. While resin, the main quality parameter of raw propolis, obtained an average below the minimum limits of the same standards. In this fraction some authors said that are the compounds to which the biological activity is attributed. The higher the value of this fraction, the better it will be in terms of performance ${ }^{24}$.

Mechanical mixtures, a visible physical characteristic showed an average below the recommended maximum limits.
The collection method, in this case, scraping, can be a great contributor in the behavior of these parameters. This method tends to incorporate many impurities such as the wax itself, remains of animals and chips from the hive. They negatively influence the behavior of parameters such as waxes, resins and impurities.

Taking this into account and considering how close to the mean values of wax and resin are to the limits proposed by the regulation of Argentina ${ }^{13}$, Brazil ${ }^{25}$ and El Salvador ${ }^{26}$. We believe that in future studies where more hives are included in the analysis and where we will influence in the availability of mango resin for bees, these values will vary ostensibly towards better results.

The oxidation index is the antioxidant capacity (associated with the biological activity of propolis). It indicates the presence of compounds with functional oxidizable groups and good oxidizing capacity, where at a higher concentration of oxidizable compounds resemble a better quality of the product. In our case, the mean obtained was very good indicating the presence of compounds of phenolic nature or with oxidizable functional groups (hydroxyls, insaturations among others), which can exhibit a good biological activity ${ }^{28}$.

\section{Conclusions}

It can be concluded that the propolis collected from the CIAPI apiary originates from the mango resin. The Mangifera indica resin and mango propolis studied qualitatively present a similar composition. Finally, mango propolis meets the requirements established by international regulations for propolis of good quality in terms of humidity, oxidation index and mechanical mixture.

\section{Conflicts of interest}

The authors declare that no conflicts of interest regarding this paper exist.

\section{Author's contributions}

DGG, JMC and LSME participated in samples collection. DGG and YNA took part in the experimental work. DGG and MF contributed in experimental design and in writing and revision of the manuscript. All authors have read and approved the final manuscript.

\section{Reference}

1. Huang S, Zhang CP, Wang K, Li G, Hu FL. Recent advances in the chemical composition of propolis. Molecules. 2014; 19: 19610-19632.

2. Anjum SI, Ullah A, Khan KA, Attaullah M, Khan $\mathrm{H}$, Ali $\mathrm{H}$, et al. Composition and functional properties of propolis (bee glue): A review. Saudi J. Biol. Sci., 2018. 
3. Hashemi JM. Biological effect of bee propolis: a review. Eur. J. Appl. Sci. 2016; 8: 311-318.

4. Aliyazicioglu R, Kanbolat S. Therapeutic Effects of Propolis: Review Article. Chem. Sci. Int. J. 2018; 24(2): 16.

5. Coelho J, Falcão SI, Vale N, Almeida-Muradian LB, VilasBoas M. Phenolic composition and antioxidant activity assessment of southeastern and south Brazilian propolis. J. Apic. Res. 2017; 56(1): 21-31.

6. Ristivojević P, Trifković J, Andrić F, Milojković-Opsenica D. Poplar-type Propolis: Chemical Composition, Botanical Origin and Biological Activity. Nat Prod Commun. 2015; 10(11): $1869-1876$.

7. Kumazawa S, Nakamura J, Murase M, Miyagawa M, Ahn MR, Fukumoto S. Plant origin of Okinawan propolis: honeybee behavior observation and phytochemical analysis. Naturwissenschaften. 2008; 95(8): 781-786.

8. Cuesta-Rubio O, Piccinelli AL, Fernandez MC, Hernández IM, Rosado A, Rastrelli L. Chemical characterization of Cuban propolis by HPLC-PDA, HPLC-MS, and NMR: the brown, red, and yellow Cuban varieties of propolis. J Agric Food Chem. 2007; 55(18):7502-9.

9. Cuesta-Rubio O, Frontana-Uribe BA, Ramırez-Apan T, Cardenas J. Polyisoprenylated Benzophenones in Cuban Propolis; Biological Activity of Nemorosone. Z Naturforsch C. 2002; 57(3-4):372-8.

10. Barreto JC, Trevisan MT, Hull WE, Erben G, de Brito ES, Pfundstein $\mathrm{B}$, et al. Characterization and quantitation of polyphenolic compounds in bark, kernel, leaves, and peel of mango (Mangifera indica L.). J Agric Food Chem. 2008; 56(14):5599-610.

11. Barreto JC, Trevisan MTS, Correia de Souza FT, Brito ES, Owen RW, Hull WE. Determinação Estrutural de Derivados de Benzofenonas de Mangifera indica Linn. por Ressonância Magnética Nuclear de $1 \mathrm{H}$ e $13 \mathrm{C}$ e EM. $34^{\text {ra }}$ reunión anual de Sociedad Brasileña de Química, 23-26 de mayo del 2011. Florianopolis. Brasil.

12. Fernández MT. Estudio del proceso de extracción y purificación de compuestos fenólicos antioxidantes a partir de hojas de mango (Mangifera indica l.), utilizando disolventes a alta presión. Tesis. Universidad de Cádiz. España. 2015.

13. Norma Argentina. IRAM-INTA 15935-1 Productos del NOA. Propóleos en bruto. Instituto Argentino de Normalización y Certificación. CNA 8925 (2008)

14. Milojkovic O, Ristivojevic P, Trifkovic J, Vovk I, Lušic D, Tešic Ž. TLC Fingerprinting and Pattern recognition
Methods in the Assessment of Authenticity of Poplar-Type Propolis. J Chromatogr Sci. 2016; 54(7): 1077-1083.

15. Stohs SJ, Swaroop A, Moriyama H, Bagchi M, Ahmad T, Bagchi D. A Review on Antioxidant, Anti-Inflammatory and Gastroprotective Abilities of Mango (Mangifera indica) Leaf Extract and Mangiferin. J Nutr Health Sci. 2018; 5(3): 302.

16. Xiao X, Shi D, Liu L, Wang J, Xie X, Kang T et al. Quercetin suppresses cyclooxygenase-2 expression and angiogenesis through inactivation of P300 signaling. PLoS One. $2011 ; 6(8)$.

17. Egert S, Bosy-Westphal A, Seiberl J, Kürbitz C, Settler U, Plachta-Danielzik S, et al. Quercetin reduces systolic blood pressure and plasma oxidised low-density lipoprotein concentrations in overweight subjects with a highcardiovascular disease risk phenotype: A double-blinded, placebo-controlled cross-over study. $\mathrm{Br} \mathrm{J}$ Nutr. 2009; 102:1065-74.

18. Pratheeshkumar $P$, Son $Y O$, Divya SP, Wang L, Turcios $L$, Roy RV, et al. Quercetin inhibits $\mathrm{Cr}(\mathrm{VI})$-induced malignant cell transformation by targeting miR-21-PDCD4 signaling pathway. Oncotarget. 2016; 8(32): 52118-52131.

19. Alarcón de la Lastra C, Martín MJ, Motilva V. Antiulcer and gastroprotective effects of quercetin: A gross and histologic study. Pharmacology.1994; 48:56-62.

20. Coles LS. Quercetin: A Review of Clinical Applications. The Chiropractic Resource Organization. Consulted on April 29, 2016.

21. Kanwal Q, Hussain I, Latif Siddiqui H, Javaid A. Antifungal activity of flavonoids isolated from mango (Mangifera indica L.) leaves. Nat Prod Res. 2010; 24(20): 1907-1914.

22. Lakhanpal $P$, Rai DK. Quercetin: A versatile flavonoid. Int J Med Update. 2007 ; 2:22-37.

23. Jürgens $C$. Factores que influyen en la producción y almacenado del propóleo. En: Vida Apícola. 2008. Consulted on Jun 13, 2019. http://www.vidaapicola.com/tecnica/manejo/almacenado.h tml.

24. Custodio A, Ferreirab M, Negri G, Salatino A. Clustering of comb and propolis waxes based on the distribution of aliphatic constituents. J. Braz. Chem. Soc. 2003; 14(3): 354-357.

25. Ministério da Agricultura. Instrução Normativa $n^{\circ} 3$ ANEXO VI - Regulamento técnico para a fixação de identidade e qualidade de própolis. Diário Oficial da República Federativa do Brasil; Brasilia: Consulted on Jan 19, 2001. http://extranet.agricultura.gov.br/sislegisconsulta/consultarLegislacao.do?operacao=visualizar\&id= 1798

Pharm \& Biosci J. 2020: 8(1); 20 
26. Norma Salvadoreña Obligatoria: Calidad de Propóleo Crudo NSO. 65.19.02:03. Acuerdo No. 555. Diario Oficial. - San Salvador, 8 de Agosto de 2003

27. Sosa LA, Maidana JF, Bedacarrasbure EL, Subovsky MJ, Ramírez SS, Castillo AE. Determinación de cinc en propóleos del nordeste argentino. Congreso Internacional de Propóleos. Memorias. Buenos Aires. Argentina. 2000.
28. Palomino LR, Martínez JP, García CM, Gil JH, Durango DL. Caracterización fisicoquímica y actividad antimicrobiana del propóleos en el municipio de La Unión (Antioquia, Colombia). Rev. Fac. Nac. Agron. Medellín. 2010; 63(1): 5373-5383. 